Rev. Adm. Saúde (On-line), São Paulo, v. 19, n. 76: e174, jul. - set. 2019, Epub 23 jul. 2019 http://dx.doi.org/10.23973/ras.76.174

ARTIGO ORIGINAL

\title{
Avaliação dos desfechos em processos licitatórios na modalidade pregão eletrônico de um hospital universitário
}

Outcomes evaluation in bidding processes in electronic trading mode of a university hospital

\section{Tiago Arantes ${ }^{1}$, Andréa Cássia Pereira Sforsin², Vanusa Barbosa Pinto ${ }^{3}$, Maria Cleusa Martins ${ }^{4}$}

1. Graduado em farmácia, especialista em farmácia hospitalar. Farmacêutico da Divisão de Farmácia do Instituto Central do Hospital das Clínicas da Faculdade de Medicina da Universidade de São Paulo (IC-HCFMUSP), São Paulo SP

2. Graduada em farmácia, especialista em farmácia hospitalar. Diretora da Divisão de Farmácia do IC-HCFMUSP, São Paulo SP

3. Graduada em farmácia, especialista em farmácia hospitalar. Diretora da Divisão de Farmácia do IC-HCFMUSP, São Paulo SP

4. Graduada em farmácia, mestre em ciências farmacêuticas. Farmacêutica chefe da Divisão de Farmácia do IC-HCFMUSP, São Paulo SP

\section{RESUMO}

O processo de aquisição de medicamentos compreende uma importante etapa do ciclo da assistência farmacêutica. Nas instituições públicas a aquisição deve ser realizada através de licitações, sendo o pregão eletrônico uma das modalidades utilizada. O estudo buscou identificar o percentual de sucesso e de fracasso nas licitações de medicamentos realizados no ano de 2012 por um hospital universitário do estado de São Paulo e estratificar os motivos que acarretaram no fracasso da compra. No período do estudo foram realizados 182 processos de compras totalizando 984 medicamentos, sendo que 496 $(50,41 \%)$ foram adquiridos e $488(49,59 \%)$ fracassaram. Dentre os motivos de fracasso na aquisição os principais foram o preço que foi considerado inaceitável $(62,10 \%)$ e a ausência de propostas (16,40\%). Conclui-se que há muitos medicamentos cujo processo de compra fracassa, porém há uma escassez de estudos que permitam comparar com outras instituições se os resultados obtidos pela licitação por pregão eletrônico são similares. 
Palavras-chave: pregão eletrônico; compras públicas; aviso de licitação.

\begin{abstract}
The process of drug procurement comprises a milestone in the pharmaceutical care cycle. In public institutions the acquisition must be made through tenders, and the electronic trading system of the modalities used. The study sought to identify the percentage of success and failure in drug procurement conducted in 2012 by a university hospital in the state of São Paulo and stratify the reasons that led to the failure of the purchase. During the study period were performed 182 procurement processes totaling 984 drugs, of which 496 (50.41\%) were acquired and 488 (49.59\%) failed. Among the reasons for failure of the main acquisition was the price that was considered unacceptable (62.10\%) and the absence of proposals (16.40\%). It is concluded that there are many drugs whose purchasing process fails, but there is a paucity of studies comparing with other institutions if the results of the bidding for electronic trading are similar.
\end{abstract}

Keywords: electronic bidding; public purchases; competitive bidding.

\title{
INTRODUÇÃO
}

O processo de aquisição de medicamentos constitui uma das atividades primordiais dentro do ciclo da assistência farmacêutica, considerando a importância desse insumo ao suporte das ações de saúde. A aquisição de medicamentos deve considerar diversos fatores: definir o que será comprado (processo de seleção), a frequência com que será comprado, quantitativo a ser adquirido (processo de programação) e a modalidade de aquisição. $O$ monitoramento e a avaliação de cada um desses processos são fundamentais para aprimorar a gestão e intervir nos problemas ${ }^{1}$.

A disponibilidade dos medicamentos e seus custos estão diretamente ligados à modalidade de aquisição adotada pela instituição, portanto o processo de gestão de compras tem um grande impacto nas finanças das instituições, bem como nos resultados do cuidado ao paciente uma vez que a falta, o uso e a aquisição inadequada do medicamento, além de aumentar os custos do processo, pode comprometer o tratamento e agravar o quadro dos pacientes que deles necessitam².

As estratégias de aquisição variam amplamente, porém a maioria dos modelos inclui atividades como quantificação da necessidade, gerenciamento da oferta, seleção de fornecedores e garantia da qualidade dos medicamentos ${ }^{2}$.

Vários fatores podem interferir no processo de gestão e aumento dos gastos com a aquisição de medicamentos, dentre eles a falta de organização e 
estruturação dos serviços farmacêuticos, falta de planejamento, demora no processo de aquisição, compras frequentes em pequenas quantidades, em regime de urgência, falta constante de medicamentos e falta de um sistema eficiente de controle e informação ${ }^{1}$.

Nas instituições públicas, a realização de licitação para aquisição de bens e serviços é determinada pela constituição e destina-se a garantir a observância do princípio constitucional da isonomia a selecionar a proposta mais vantajosa para a Administração Pública, acrescidos de celeridade, oralidade, concentração dos atos e razoabilidade, que estão descritos na Lei 10.520/2002, que institui a modalidade de licitação denominada pregão ${ }^{3,4,5}$.

A licitação é composta por duas fases, a fase interna onde estão relacionados os procedimentos que antecedem a divulgação do edital: estimativa de consumo e determinação da quantidade e periodicidade a ser comprada, pesquisa de preços para utilizar como referência, tipo de embalagem, prazos e condições de entrega dos bens licitados. A fase externa, que tem início na divulgação do edital, e ainda compreende a habilitação, julgamento das propostas, adjudicação, homologação, anulação e revogação, sendo que na modalidade pregão são acrescidas as fases de credenciamento, seleção, lances e negociação ${ }^{6,7}$.

O pregão constitui a modalidade de licitação utilizada para a aquisição de bens e serviços que propicia inúmeros benefícios, como transparência, ampliação de oportunidades de participação, competição e celeridade no processo de aquisição; redução dos preços, diminuição dos custos operacionais e o período de duração do certame? .

Diversos trabalhos descrevem a importância dessa modalidade de licitação, principalmente devido as suas vantagens para a administração pública. Dentre estas, maior transparência do processo, ampliação do número de fornecedores interessados em participar dos certames, maior agilidade nas compras com diminuição do tempo gasto, maiores descontos obtidos resultando em uma economia significativa para administração pública ${ }^{8}$.

Segundo Vasconcellos ${ }^{6}$, o pregão eletrônico é a modalidade de licitação que apresenta o maior conjunto de pontos positivos para a administração pública, principalmente devido ao aumento da concorrência e redução significativa dos preços praticados. Outro aspecto relevante deve-se ao fato do pregão eletrônico ser considerado a modalidade licitatória que apresenta menor risco quanto à lisura do processo, pois dificulta a combinação de preços entre os concorrentes ${ }^{9}$.

Segundo Faria et al. ${ }^{10}$, em média, o aumento de um fornecedor no pregão proporciona uma redução de $1,235 \%$ dos preços, relação parecida com a identificada por Silva (2007) que foi de $1,07 \%$ de redução, confirmando a expectativa de que 0 aumento no número de participantes na licitação resulta em redução de custos, devido ao acirramento da disputa.

Monteiro et al. ${ }^{11}$, analisaram doze processos realizados pelo Hospital Universitário da Universidade Federal do Maranhão (HUUFMA) referentes ao 
período de 2007 (471 itens) e doze processos referentes ao período de 2008 (425 itens) e identificou respectivamente $71,34 \%$ e $60,24 \%$ de sucesso nas licitações, porém o estudo não contemplou todos os pregões eletrônicos realizados no período.

Considerando que a implantação do pregão eletrônico apresentou um grande avanço nos processos de aquisição, desburocratizando e otimizando as compras da administração pública, bem como, reduzindo os valores praticados nas licitações, o objetivo do presente estudo é avaliar os desfechos dos processos licitatório, por meio da modalidade pregão eletrônico para registro de preços para aquisição futura de medicamentos, pois no que concerne aos desfechos, itens adquiridos e fracassados, a literatura é escassa de informação.

\section{Considerações acerca da licitação}

A licitação é um procedimento obrigatório para toda e qualquer entidade pública e prevê como modalidade a concorrência, a tomada de preços, o convite, o concurso e o leilão, cuja diferença básica consiste na diferença do valor estimado ou complexidade da licitação 4 .

Para realizar a gestão das compras e contratações, diretas ou por meio do pregão, o Governo do Estado de São Paulo criou dois portais eletrônicos, um para a realização das operações de menor valor (dispensa de licitação e convite) que são enquadráveis nos limites da Bolsa Eletrônica de Compras (BEC) e outro para o registro das operações realizadas pela modalidade do pregão' ${ }^{12}$.

A BEC, fundamentada pelo Decreto no 46.074, de 30.08.2001, é um sistema eletrônico de negociação de preços que facilita o processo de compra e venda entre as Unidades Gestoras Executoras e os fornecedores cadastrados do Estado, racionalizando e facilitando uma complexa rotina interna, transformando-a em um simples procedimento tecnológico ${ }^{13}$.

O pregão eletrônico para o sistema de registro de preços adotado pelo Hospital das Clínicas da Faculdade de Medicina da Universidade de São Paulo (HCFMUSP), para aquisição futura de bens é regido pela Lei Federal no 10.520 , de 17 de julho de 2002, pelo Decreto $n^{\circ} 49.722$, de 24 de junho de 2005, pelo regulamento anexo a Resolução n ${ }^{\circ}$ CC-27, de 25/05/2006, aplicando-se, subsidiariamente, no que couberem, as disposições da Lei federal o 8.666, de 21 de junho de 1993, da Lei estadual oㅜ 6.544, de 22 de novembro de 1989, do Decreto estadual $n^{\circ} 47.297$, de 06 de novembro de 2002, da Resolução CEGP-10, de 19 de novembro de 2002, e demais normas regulamentares aplicáveis à espécie. O HCFMUSP começou a operacionalizar no sistema BEC em maio de $2003^{14}$.

Embora a Lei Federal 10.520 tenha facultado a divulgação dos processos em meios eletrônicos, uma determinação estadual estabelece a divulgação dos 
avisos dos pregões por intermédio de meio eletrônico, juntamente com a publicação na imprensa oficial ${ }^{5}$.

\section{METODOLOGIA}

O estudo consiste na análise retrospectiva dos processos licitatórios na modalidade pregão eletrônico para registro de preços para aquisição futura de medicamentos, realizados pelo HCFMUSP e aprovado pelo Comitê de Ética em Pesquisa da Faculdade de Medicina da Universidade de São Paulo sob o número 358/2015.

Foram incluídos no estudo todos os processos de aquisição de medicamentos realizados de janeiro a dezembro de 2012, na modalidade pregão eletrônico para registro de preços, sendo que foram excluídos os pregões presenciais internacionais, os pregões para aquisição de produtos para a saúde (material médico hospitalar), material de laboratório, alimentos, equipamentos em geral, pregões para aquisição de serviços e pregões presenciais para aquisição de medicamentos importados.

Para identificar os processos licitatórios, foi realizada a busca no portal do HCFMUSP, que disponibiliza todas as ordens de compras, onde foram identificados os processos pertinentes à aquisição de medicamentos. Após a identificação das ordens de compras de medicamentos, foi efetuada a busca dos resultados desses processos no portal eletrônico da BEC, onde é possível acessar integralmente as atas dos pregões finalizados.

\section{RESULTADOS E DISCUSSÃO}

Os resultados obtidos referem-se ao levantamento e análise dos pregões eletrônicos para aquisição de medicamentos do HCFMUSP. Foram realizados 182 processos de registro de preço, correspondendo a $100 \%$ dos processos realizados em 2012, para a aquisição de medicamentos, totalizando 984 itens (medicamentos), conforme demonstrado na Tabela 1.

Tabela 1. Distribuição dos pregões eletrônicos de acordo com o mês de realização, a quantidade e porcentagem de processos, a quantidade e a porcentagem de itens licitados

\begin{tabular}{lrrrr}
\hline & \multicolumn{2}{c}{ Número de processos } & \multicolumn{2}{c}{ Número de itens } \\
Mês & Quantidade & $\%$ & Quantidade & $\%$ \\
\hline Janeiro & 11 & 6,04 & 100 & 10,16 \\
Fevereiro & 3 & 1,65 & 23 & 2,34
\end{tabular}




\begin{tabular}{lrrrr} 
Março & 17 & 9,34 & 74 & 7,52 \\
Abril & 21 & 11,54 & 153 & 15,55 \\
Maio & 19 & 10,44 & 96 & 9,76 \\
Junho & 12 & 6,59 & 77 & 7,83 \\
Julho & 22 & 12,09 & 116 & 11,79 \\
Agosto & 11 & 6,04 & 33 & 3,35 \\
Setembro & 18 & 9,89 & 86 & 8,74 \\
Outubro & 22 & 12,09 & 118 & 11,99 \\
Novembro & 6 & 3,30 & 18 & 1,83 \\
Dezembro & 20 & 10,99 & 90 & 9,15 \\
\hline TOTAL & $\mathbf{1 8 2}$ & $\mathbf{1 0 0 , 0 0}$ & $\mathbf{9 8 4}$ & $\mathbf{1 0 0 , 0 0}$
\end{tabular}

Dos 984 itens licitados 496 (50,41\%) tiveram sucesso no processo de aquisição, porém 488 itens $(49,59 \%)$ tiveram a compra fracassada, conforme descrito na Tabela 2.

Tabela 2. Quantidade de medicamentos licitados, fracassados e adquiridos

Quantidade de medicamentos

\begin{tabular}{lrrrrr} 
Mês & Licitados & Fracassados & $\%$ & Adquiridos & $\%$ \\
\hline Janeiro & 100 & 62 & 62,00 & 38 & 38,00 \\
Fevereiro & 23 & 14 & 60,87 & 9 & 39,13 \\
Março & 74 & 41 & 55,41 & 33 & 44,59 \\
Abril & 153 & 64 & 41,83 & 89 & 58,17 \\
Maio & 96 & 43 & 44,79 & 53 & 55,21 \\
Junho & 77 & 48 & 62,34 & 29 & 37,66 \\
Julho & 116 & 49 & 42,24 & 67 & 57,76 \\
Agosto & 33 & 18 & 54,55 & 15 & 45,45 \\
Setembro & 86 & 50 & 58,14 & 36 & 41,86 \\
Outubro & 118 & 55 & 46,61 & 63 & 53,39
\end{tabular}




\begin{tabular}{lrrrrr} 
Novembro & 18 & 6 & 33,33 & 12 & 66,67 \\
Dezembro & 90 & 38 & 42,22 & 52 & 57,78 \\
\hline TOTAL & $\mathbf{9 8 4}$ & $\mathbf{4 8 8}$ & $\mathbf{4 9 , 5 9}$ & $\mathbf{4 9 6}$ & $\mathbf{5 0 , 4 1}$
\end{tabular}

A Tabela 3 mostra os motivos dos 488 medicamentos terem o processo fracassado, sendo que 303 ocorreram devido aos preços praticados pelos licitantes terem sido considerados inaceitáveis pela instituição, 80 foram desertos (itens que não tiveram nenhuma proposta, ou seja, ausência de licitantes interessados em fornecer os medicamentos), 29 foram revogados pela instituição, 29 por apresentar o Certificado de Boas Práticas de Fabricação (CBPF) com validade expirada, 13 por apresentar CBPF com endereço do polo fabril diferente do registrado na bula do produto, 7 não apresentaram o CBPF, 5 se identificaram na proposta, 3 apresentaram o registro do medicamento com a validade expirada, 3 apresentaram a proposta com validade inferior a requisitada no edital, 2 não apresentaram a bula do produto, 1 apresentou a documentação ilegível impossibilitando a análise do parecerista, 4 (0,82\%) foram propostas de farmácia de manipulação e $9(1,84 \%)$ fracassaram na fase de habilitação por problemas relacionados à documentação exigida.

Tabela 3. Motivos dos fracassos nos processos de aquisição de medicamentos.

\begin{tabular}{lrr}
\hline Motivos dos fracassos & No itens & $\%$ \\
\hline Preço Inaceitável & 303 & 62,10 \\
Deserto & 80 & 16,40 \\
Revogado & 29 & 5,95 \\
CBPF - Vencido & 29 & 5,95 \\
CBPF - Endereço diferente da bula & 13 & 2,66 \\
CBPF - Falta & 7 & 1,43 \\
Identificação na proposta & 5 & 1,02 \\
Registro Vencido Ministério da Saúde & 3 & 0,61 \\
Validade da Proposta & 3 & 0,61 \\
Falta de Bula & 2 & 0,41 \\
Documento llegível & 1 & 0,20 \\
Proposta de farmácia de manipulação & 4 & 0,82
\end{tabular}


Verifica-se neste estudo que o número de medicamentos que obtiveram êxito (496) no processo licitatório foi semelhante ao número de itens que fracassaram (488). Comparando com os resultados obtidos por Monteiro et al. ${ }^{11}$, há uma significativa diferença, pois em 2007 e 2008 prosperaram respectivamente $71,34 \%$ e $60,24 \%$ dos itens (Gráfico 1).

Entretanto deve-se considerar que o número de itens licitados em 2007 (471) e 2008 (425) no estudo realizado por Monteiro et al. ${ }^{11}$, foram inferiores aos obtidos no presente estudo, que foram 984 itens em 2012.

Gráfico 1. Comparativo entre os resultados obtidos nos processos de compra de medicamentos por pregão eletrônico do HUUFMA e do HCFMUSP.

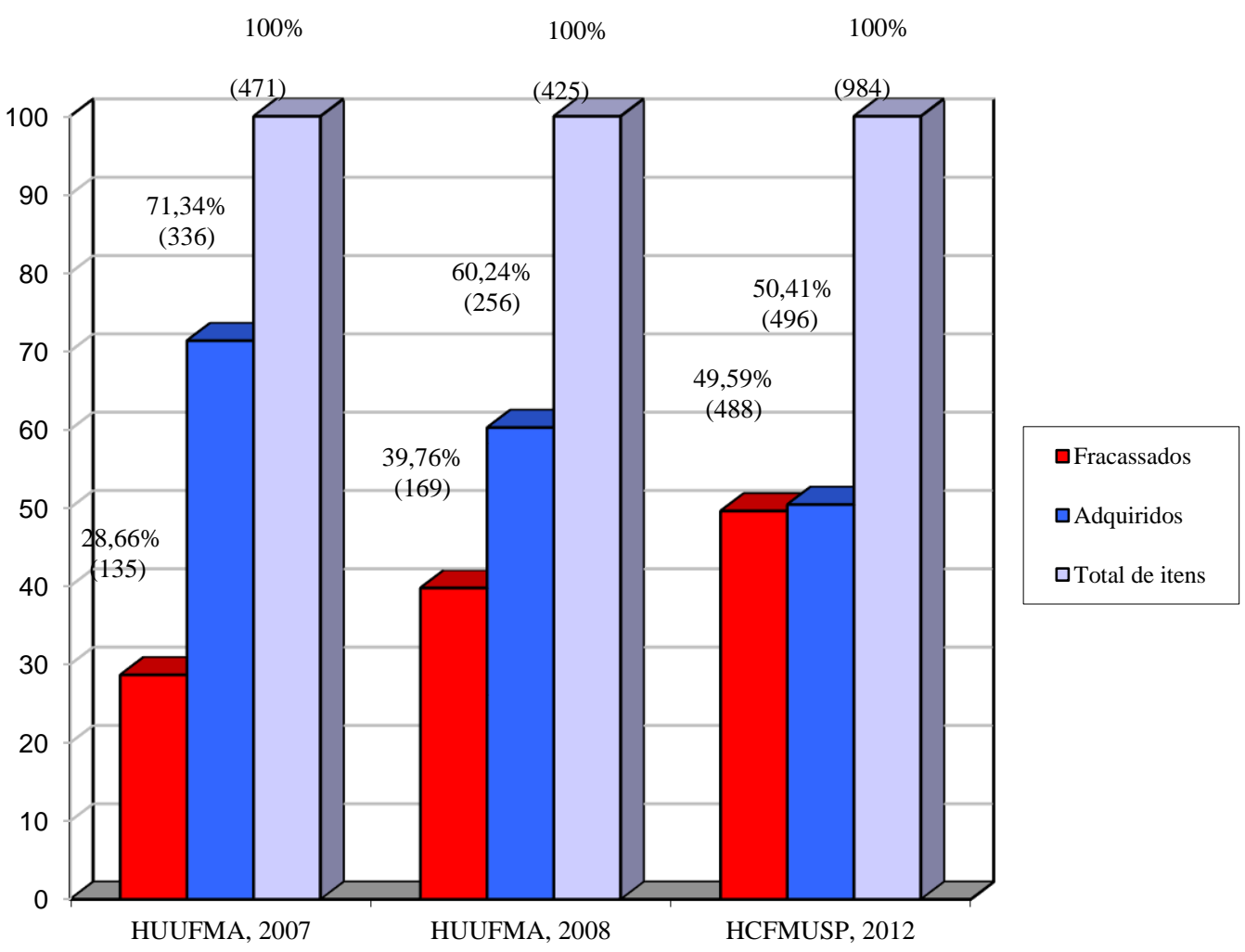


Analisando os motivos que acarretaram no fracasso da aquisição dos medicamentos, foi identificado que $303(62,10 \%)$ itens não foram adquiridos, pois os preços praticados pelos licitantes estavam acima dos valores considerados aceitáveis pela instituição.

Os valores utilizados como referenciais são obtidos através de uma análise de preços de mercado, preço da última aquisição pela instituição e preços registrados por em outras instituições públicas.

A ausência de propostas, denominada de deserto, foi a segunda maior causa de fracassos na compra, resultando em $80(16,40 \%)$ itens não comprados. Dentre os motivos que podem acarretar em deserto, pode-se considerar o desconhecimento da licitação por parte do fornecedor, a falta de interesse em fornecer os quantitativos estimados em edital pela administração pública (pequenas quantidades ou quantitativos extremamente altos) e desinteresse em participar por insucessos anteriores em virtude da dificuldade de atingir o preço desejado pela administração pública.

Considerando os fracassos ocasionados por preço inaceitável e por deserto, identificou-se que esses motivos representaram $78,5 \%$ (383) dos desfechos negativos nos pregões eletrônicos enquanto os demais motivos resultaram em $21,5 \%$ (105) dos fracassos (Gráfico 2).

Gráfico 2. Comparativo entre os motivos de fracasso nos processos licitatórios para aquisição de medicamentos. 


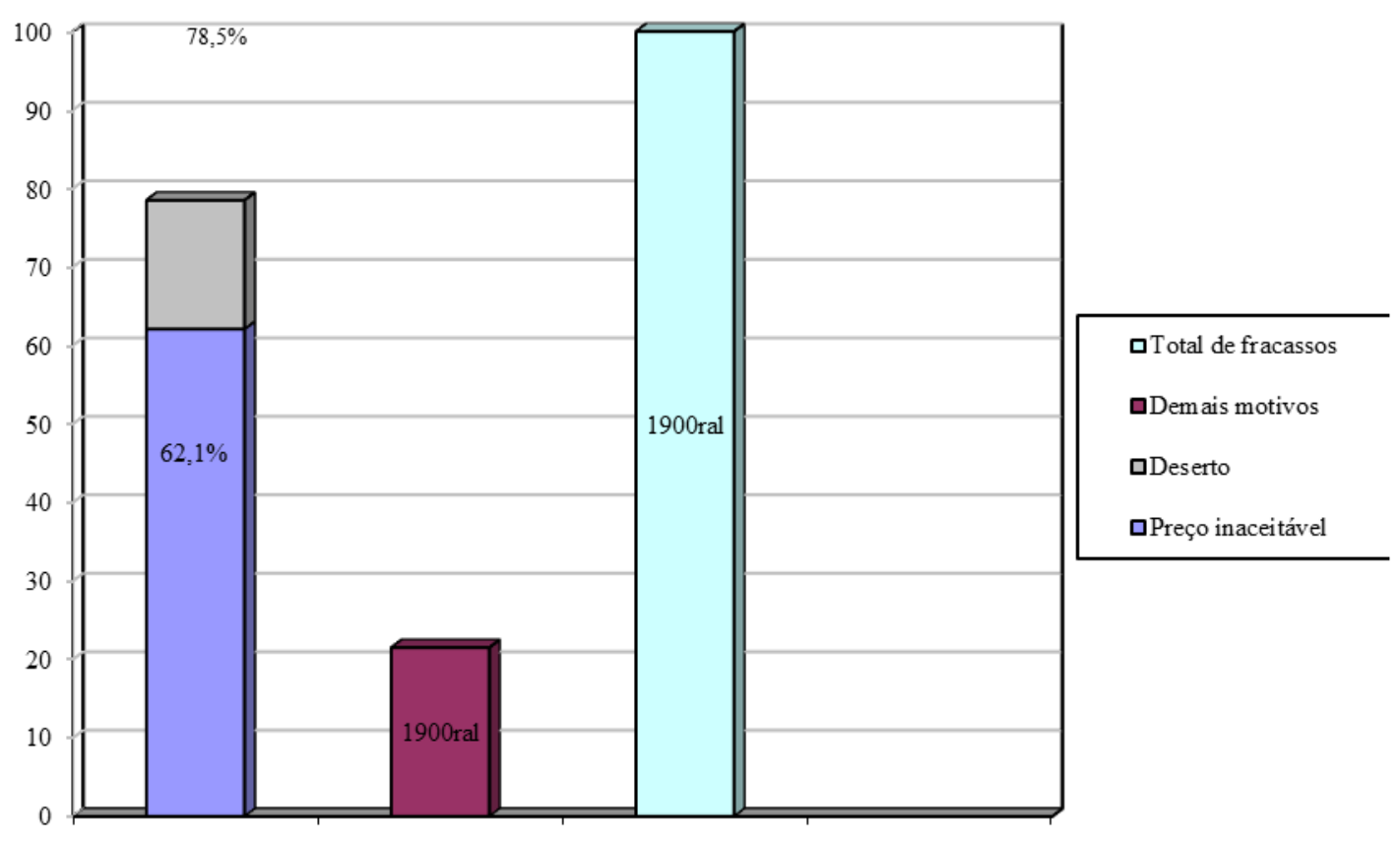

A Revogação dos itens licitados representou 29 (5,95\%) dos medicamentos não adquiridos, sendo que a maior parte das revogações ocorreu devido a alterações que precisavam ser efetuadas no memorial descritivo, como detalhamento da apresentação e especificação de indicação para uso em pediatria. Desta forma, se os ajustes fossem detectados antes da publicação do edital ou até mesmo em tempo hábil antes da data do pregão, seria possível realizar os ajustes necessários e republicar o edital sem perdas para a administração pública.

O CBPF é um documento emitido pela Agência Nacional de Vigilância Sanitária (ANVISA) atestando que determinado estabelecimento cumpre com as boas práticas de fabricação e descreve para cada linha de produção, as formas farmacêuticas e os insumos farmacêuticos para os quais o estabelecimento encontra-se em conformidade com os requisitos preconizados pelas normas vigentes ${ }^{15,16}$. Dos itens fracassados cujo motivo esteja relacionado ao CBPF, $29(5,95 \%)$ itens estavam com o certificado vencido, $13(2,66 \%)$ itens fracassaram, pois o documento apresentava polo fabril diferente do registrado em bula (onde consta a unidade de fabricação do medicamento) e $7(1,43 \%)$ itens não prosperaram, pois os licitantes não apresentaram o certificado junto com a proposta. Os fatores de insucesso na licitação relacionados ao certificado poderiam ser minimizados se as empresas adotassem medidas visando a revisão de todos os documentos exigidos no certame, para identificar se estão dentro do período de vigência e se correspondem a unidade de fabricação do medicamento licitado.

Durante o procedimento de anexação das propostas no site da BEC é importante certificar-se de que não há elementos no arquivo que permita a 
identificação do licitante conforme rege o Decreto Federal $n^{0}$ 5.450/200517, porém $5(1,02 \%)$ itens tiveram o processo de aquisição cancelados pois as propostas possuíam caracteres, símbolos ou siglas nas propriedades do documento. Esse tipo de erro facilmente poderia ser evitado se as empresas efetuassem a leitura do manual do pregão eletrônico disponível no site da BEC onde consta detalhadamente a forma de gerar um arquivo sem caracteres de identificação.

Os medicamentos para serem comercializados no Brasil necessitam de registro junto ao Ministério da Saúde (MS) e a validade do registro deve estar vigente ${ }^{18}$. Entretanto o processo de aquisição de $3(0,61 \%)$ medicamentos não prosperaram em virtude de os licitantes terem apresentado o referido registro com a validade expirada e sem o protocolo de renovação junto ao Ministério da Saúde.

As propostas apresentadas pelos licitantes devem conter registrado o prazo de validade da proposta, que deve estar de acordo o exigido no edital, porém 3 $(0,61 \%)$ itens fracassaram, pois, as empresas colocaram prazos diferentes dos exigidos.

A bula do medicamento deve ser apresentada junto à proposta para a análise técnica, entretanto a aquisição de $2(0,41 \%)$ itens foi cancelada, pois os fornecedores não apresentaram o documento. A bula é fundamental para que 0 parecerista possa identificar as informações do produto ofertado (princípio ativo, nome comercial, dados do fabricante, registro no MS, dados do responsável técnico e polo fabril) e verificar se estão de acordo com item licitado.

Os licitantes devem apresentar documentos legíveis para análise dos pareceristas, porém $1(0,20 \%)$ item fracassou pois os documentos apresentados estavam ilegíveis, impossibilitando identificar o medicamento ofertado com o licitado e a vigência da documentação.

Os outros dois motivos que resultaram no fracasso do processo de aquisição foram devido a propostas realizadas por farmácias de manipulação (4) que resultaram em $0,82 \%$ dos desfechos negativos e desclassificações na fase de habilitação (9) em virtude de problemas com a documentação exigida, impactando em 1,84\%. Referente a fase de habilitação, para participação no pregão eletrônico, o licitante deve manifestar que cumpre plenamente todos os requisitos, preenchendo o campo próprio do sistema eletrônico e que sua proposta está em conformidade com as exigências do instrumento convocatório, portanto os licitantes desclassificados por não apresentarem a documentação exigida nesta fase podem estar sujeitos a sanções previstas na legislação ${ }^{17}$.

\section{CONCLUSÃO}

Considerando o grande número de itens fracassados, podemos dizer que este procedimento deve ser analisado de forma crítica com a finalidade de identificar 
os reais motivos que estão acarretando nesse desfecho, que resulta em retrabalho, pois os itens que não prosperaram necessitarão de novos processos licitatórios para que a instituição consiga efetuar a aquisição.

Baseado nos resultados do estudo algumas ações podem ser desencadeadas com o intuito de promover um melhor aproveitamento das licitações, como identificar se os preços praticados pela administração pública estão de acordo com os preços praticados por outros órgãos públicos e verificar se existe a necessidade de otimizar a dinâmica de realinhamento dos preços.

Para os fatores que fizeram com que uma parcela significativa dos itens não tivesse nenhuma proposta, pode-se melhorar o processo de divulgação da licitação, identificar e buscar no mercado novos fornecedores e trabalhar junto aos licitantes desclassificados métodos de disseminação da documentação e critérios exigidos na licitação, visando a redução dos fracassos por falta de documentos ou por apresentação de documentos com validade expirada.

É importante ressaltar também que outros fatores estão envolvidos em uma licitação, como a qualificação e experiência do pregoeiro na condução da negociação, o tempo que o parecerista possui para análise técnica das propostas e os valores referentes aos custos de elaboração de um processo de compras, que neste caso necessitará ser realizado novamente, respeitando todos os prazos legais. Nesses casos, quando o processo de compras fracassa, deve-se considerar todos esses fatores, pois dependendo da necessidade do medicamento pela área assistencial e dos novos prazos para elaboração e publicação do edital, realização do pregão, homologação e finalização com o recebimento do medicamento, podem ocorrer rupturas no atendimento impactando na qualidade da assistência prestada.

\section{REFERENCIAS}

1. BRASIL. Ministério da Saúde. Secretaria de Ciência, Tecnologia e Insumos Estratégicos. Departamento de Assistência Farmacêutica e Insumos Estratégicos. Aquisição de medicamentos para assistência farmacêutica no SUS: orientações básicas / Ministério da Saúde, Secretaria de Ciência, Tecnologia e Insumos Estratégicos, Departamento de Assistência Farmacêutica e Insumos Estratégicos. - Brasília: Ministério da Saúde, 2006.56 p.

2. Centro Brasileiro de Informação sobre Medicamentos (CEBRIN). Rename 2002 e o Ciclo Gerencial da Assistência Farmacêutica: Sugestões para a Conferência Nacional de Política de Medicamentos e Assistência Farmacêutica. Pharmacia Brasileira, ano VII, n. 7, p. 47-50, ago/set. 2002.

3. BRASIL. Constituição (1988). Constituição da República Federativa do Brasil. Brasília, DF: Senado, 1988. Disponível em: <http://www.planalto.gov.br/ccivil 03/constituicao/constituicao.htm>. 
4. BRASIL. Lei $n^{\circ} 8.666$ de 21 de junho de 1993. Regulamenta o art. 37, inciso XXI, da Constituição Federal, institui normas para licitações e contratos da Administração Pública e dá outras providências. Disponível em: <http://www.planalto.gov.br/ccivil 03/Leis/L8666cons.htm>.

5. BRASIL. Lei $n^{0} 10.520$ de 17 de julho de 2002. Institui, no âmbito da União, Estados, Distrito Federal e Municípios, nos termos do art. 37, inciso XXI, da Constituição Federal, modalidade de licitação denominada pregão, para aquisição de bens e serviços comuns, e dá outras providências. Disponível em: <http://www.planalto.gov.br/ccivil 03/leis/2002/l10520.htm>.

6. VASCONCELLOS F. Licitação pública: análise dos aspectos relevantes do pregão. Prima Facie International Journal, v. 4, n. 7, p. 151-163, jul/dez. 2005.

7. VIEIRA MR. Licitação: A vantagem do pregão eletrônico nas licitações. Monografia (Graduação) - Universidade Federal do Rio Grande do Sul, Porto Alegre, 2010.

8. SILVA, A.A. Economia das compras governamentais em decorrência do pregão eletrônico - uma abordagem econométrica. Dissertação (Mestrado) - Centro de Aperfeiçoamento dos Economistas do Nordeste, Universidade Federal do Ceará, Fortaleza, 2007.

9. BEZERRA JEV. O pregão eletrônico como base para minimizar custos da gestão pública. Monografia (Graduação) - Centro Universitário de João Pessoa, João Pessoa, 2008.

10.FARIA ER, et al. Fatores determinantes na variação dos preços dos produtos contratados por pregão eletrônico. Revista de Administração Pública, v. 44, n. 6, p. 1405-1428, nov/dez. 2010.

11. MONTEIRO, F; et al. Pregão eletrônico para aquisição de medicamentos: experience of an university hospital. Revista do Hospital Universitário UFMA, v. 10, n. 2, p. 50-57, mai/ago, 2009.

12.SPRICIGO PR, FONSECA SA. Inovações nos procedimentos de compras e contratações na administração pública: breve avaliação das contribuições do pregão. Temas de Administração Pública, v. 2, n. 3, p. 1-12, 2008.

13. BRASIL. Decreto no 46.074, de 30 de agosto de 2001. Aprova o regulamento para compra de bens, para entrega imediata, em parcela única, mediante licitação na modalidade de Convite, tipo menor preço, em processo eletrônico, realizado por intermédio do Sistema BEC/SP - Bolsa Eletrônica do Estado de São Paulo, e dá providencias correlatas. Disponível em:

$<$ http://www.al.sp.gov.br/repositorio/legislacao/decreto/2001/decreto4607430.08.2001.html>

14. Hospital das Clínicas da Faculdade de Medicina da Universidade de São Paulo (HCFMUSP). Bolsa Eletrônica de Compras (BEC), 2012. Disponível em: <http://www.hcnet.usp.br/adm/ual/pregao/index.htm>. 
15.BRASIL. Agência Nacional de Vigilância Sanitária. Resolução RDC № 39 , de 14 de agosto de 2013. Dispõe sobre os procedimentos administrativos para concessão da Certificação de Boas Práticas de Fabricação e da Certificação de Boas Práticas de Distribuição e/ou Armazenagem.

Disponível em: $<$ http://bvsms.saude.gov.br/bvs/saudelegis/anvisa/2013/rdc00391408 20 13.pdf>.

16. BRASIL. Ministério da Saúde. Portaria oㅡ 2.814 de 29 de maio de 1998. Estabelece procedimentos a serem observados pelas empresas produtoras, importadoras, distribuidoras e do comercio farmacêutico. Diário Oficial da União, Brasília, DF, 18.11.1998.

17. BRASIL. Decreto no 5.450, de 31 de maio de 2005. Regulamenta o pregão, na forma eletrônica, para aquisição de bens e serviços comuns, e dá outras providências. Disponível em:

$<$ http://www.planalto.gov.br/ccivil 03/ ato20042006/2005/decreto/d5450.htm>.

18. BRASIL. Lei no 6.360 de 23 de setembro de 1976. Dispõe sobre a vigilância sanitária a que ficam sujeitos os medicamentos, as drogas, os insumos farmacêuticos e correlatos, cosméticos, saneantes e outros produtos, e dá outras providências. Disponível em: $<$ http://portal.anvisa.gov.br/wps/wcm/connect/f262da004745968d9e62de3fb c4c6735/legis 6360.pdf?MOD=AJPERES>.

Recebido: 27 de junho de 2019. Aceito: 23 de julho de 2019

Correspondência: Tiago Arantes. Instituto Central, HCFMUSP - Rua Dr. Enéas Carvalho de Aguiar, $255-7^{\circ}$ andar, sala 7113 - Cerqueira César - CEP 05403-900 - São Paulo (SP). E-mail: drtiagoarantes@hotmail.com

Conflito de Interesses: os autores declararam não haver conflito de interesses. 
